\title{
The Initiation of Safety-Enhancing Actions in Railway Crossings Using Modelling Procedures
}

\author{
L. Szabó ${ }^{1}$, M. Somogyi ${ }^{2}$, G. Horváth ${ }^{1}$ \\ ${ }^{1}$ Széchenyi István University, Department of Transport \\ Egyetem tér 1, 9026 Győr, Hungary \\ E-mail: szala@sze.hu \\ ${ }^{2}$ Széchenyi István University, Department of Automation \\ Egyetem tér 1, 9026 Győr, Hungary
}

Abstract: This study is examining the application opportunities of models, and it is revealing a possible solution which can be the basis of creating a catalogue which can establish the reconstruction of railway crossings. This reconstruction catalogue is suggesting infrastructure changes and new traffic management procedures with taking account of the controlled model outputs. Based on the reconstruction catalogue, feasibility studies and construction project documentations can be made.

Keywords: hazard ranking, degree of traffic safety risk, system of revision aspects, Evaluation Matrix, reconstruction catalogue

\section{Introduction}

The dangerous characteristics of railway crossings come from the fact that a crossing is a contact point of different traffic systems, where structurally different traffic paths cross each other. These different kinds of paths are used by vehicles with significantly different technical parameters. Therefore the railway crossings have prominent importance in terms of traffic safety. Because of the facts above, and in addition due to a ministerial instruction released in 2003 , the most dangerous railway crossings must be determined. The basis of this determination is an establishment of a hazard ranking. This hazard ranking can be created using a total score per crossings indicator generated by a data processing algorithm. Within the project called 'Safety Inspection of Railway Crossings in the Area of Railway Track Sections Extended to the Border of Burgenland and West Hungary' (Sicherheitsinspektionen von Eisenbahnkreuzungen entlang der grenzüberschreitenden Bahnlinien in Burgenland und Westungarn - SIEBaBWe) by the examination of several possible modelling techniques we created a model which is suitable not only for the determination of the railway crossings' hazard ranking in our project, but also it is applicable for every railway crossings. The point creation was the common element in the potentially attractive models; the method of this point creation meant the difference. Regarding to certain models a mentionable common feature was the demand of counting with the environmental characteristics of railway crossings, the 
accident and traffic data and the way of insurance The railway crossing, where the implementation of safety-enhancing actions are the most reasoned, can be designated by model outputs which are checked and filled with proper data.

\section{The Accidental Status of Railway Crossings on the GySEV's Hungarian Network}

The Government Regulation Number 168 of 2010 (V.11.) is about the listing of national mainline network, regional and other railway tracks. Within the project SIEBaBWe mentioned in the introduction, 23 railway crossings were mulitcriterially examined on the Hungarian Network of GySEV. The Table 1 contains the line group distribution of railway crossings.

Table 1. Distribution of the Examined Railway Crossings

\begin{tabular}{|c|c|}
\hline Line type & Number of Railway Crossings (pc) \\
\hline 1 & 14 \\
\hline 2 & 7 \\
\hline 3 & 2 \\
\hline 1 & 14 \\
\hline
\end{tabular}

1: Railway track operated as a part of the Trans-European rail freight traffic network

2: National mainline network track which is not a part of the Trans-European rail freight network

3: Regional railway track

The selected railway crossings are showing a pretty various image in the aspect of technological features and other safety-enhancing factors, however these crossings are totally applicable for every existing provisions and regulations according to the special authorities' qualification. Table 2 contains the accidental data from 2001 to 2012 within the framework of the project.

Table 2. The Change of Accidents in Railway Crossings on the GySEV's Network

\begin{tabular}{|c|c|c|c|c|}
\hline Year & Accident (pc) & Died (pc) & Wounded (pc) & $\begin{array}{c}\text { Property } \\
\text { damage (HUF) }\end{array}$ \\
\hline 2001 & 2 & 0 & 0 & 2623018 \\
\hline 2002 & 8 & 4 & 6 & 2865554 \\
\hline 2003 & 3 & 0 & 3 & 272102 \\
\hline 2004 & 4 & 0 & 5 & 1857166 \\
\hline 2005 & 5 & 1 & 3 & 1863862 \\
\hline 2006 & 4 & 0 & 2 & 1547281 \\
\hline 2007 & 8 & 1 & 4 & 136368412 \\
\hline
\end{tabular}




\begin{tabular}{|c|c|c|c|c|}
\hline 2008 & 7 & 7 & 2 & 137344914 \\
\hline 2009 & 1 & 1 & 2 & 61437611 \\
\hline 2010 & 0 & 0 & 4 & 565330 \\
\hline 2011 & 2 & 2 & 3 & 1456929 \\
\hline $2012+$ & 9 & 8 & 11 & 12150303 \\
\hline
\end{tabular}

+ : Jan. 2012 - Nov. 2012

The average distance of railway crossings is 1430 meters on the 434.7 kilometres long network, and 89217 trains has travelled on the examined network per year. There are 87 station and 217 line crossings of the railway crossings.

Analyzing the accidents we made the following major statements:

The following conventions should be taken into account.

- the accidents happened mainly in secured railway crossings.

- the most serious accidents happened in crossings which have small or average traffic

- the essential reason of accidents (99\%) comes from the violation of Road Traffic Regulations

- $\quad$ more and more frequently the accidents are caused by improper behaviour

- the accidents also happened despite the locomotive's sound signal

- $\quad$ the property damages comes from accidents have significantly increased

- the technological developments couldn't significantly reduce the number of accidents

- $\quad$ peaks and troughs can be observed in the changes of the accident numbers

- $\quad$ property damages have increased in more modern railway crossings.

Analyzing the accidents had confirmed more the necessity of raising awareness in every age groups of the society.

\section{The Examination of the Practicable Model Versions}

In this chapter we introduce two modelling techniques which had been considered suitable by the working committee established within the project's framework for determining the hazard raking of the railway crossings. Speaking about the content and the actuality of the reachable data is necessary, regardless of the suitable modelling technique's type. The source of these data is the National Transport Authority, the Track Facilities Department of the MÁV Zrt., the Magyar Közút Nonprofit Zrt. (Hungarian Public Road Non-profit Ltd.), and the recordings of the railway companies. The railway companies are registering every event which happens in a railway crossing, whether it is an accident comes with personal injury or an accident which causes 
property damage. The ranking practice of the past years met incomplete, wrong, old or non-recorded data. According to the experts' concordant opinion, a central database would be needed which should be based onto the road crossings' GPS coordinates assigned to the sum of digitally recorded data of the given railway crossing. Controlling the updates of databases would lead to further improvement.

\section{1. „The GySEV model” [1]}

The model made available by GySEV generates a ranking which shows the railway crossings' degree of traffic safety risk compared to each other. In this model the maximum given score of the certain railway crossings is determined. This maximum score will be distributed among the crossings' specific factors. These factors are:

- the numbers and results of accidents in the crossing

- the road and rail traffic of the railway crossing

- the safety equipment installed in the crossing

- other characteristics (Fig. 1).

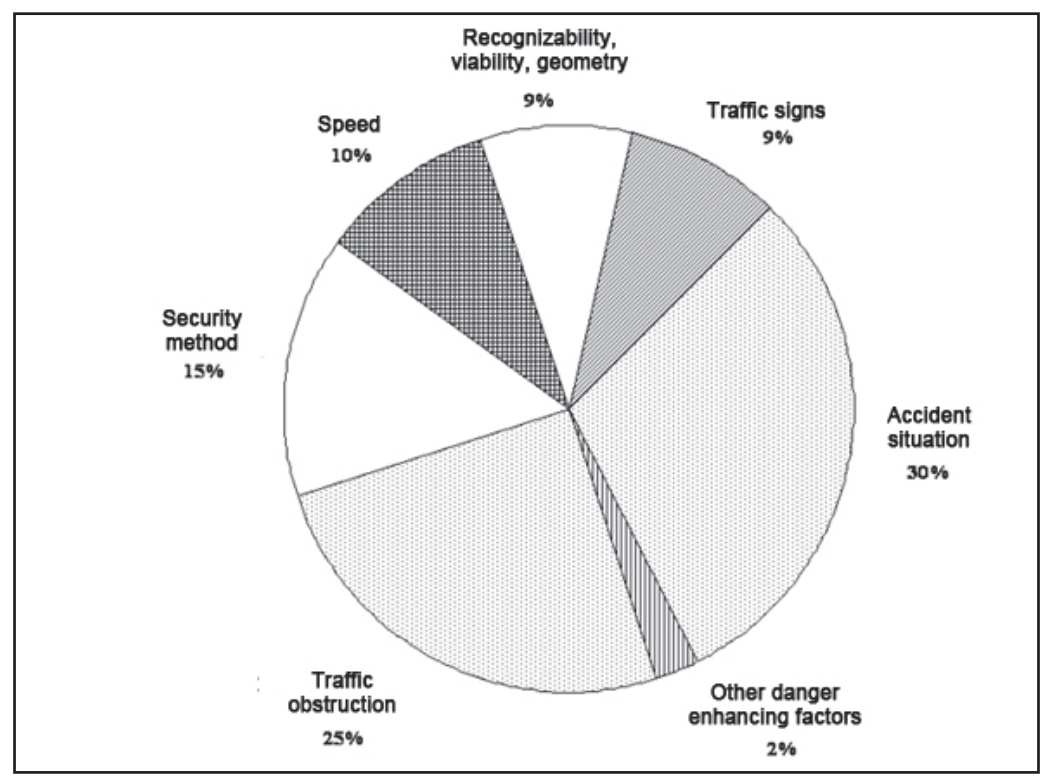

Figure 1.

Percentage Distribution of Maximum Assignable Scores by Indicator Groups [1]

The ranking system uses correlations in the case of every factor. 


\subsubsection{Accidental status}

The assignable score contains events in the railway crossing from the past ten years. The events (accidents) which happened more than five years ago are counted with 50\% relevance.

$$
\mathrm{S}_{\mathrm{a}}=300 * \frac{\ln \left(\mathrm{N}_{\mathrm{e}}+0,05\right)}{\mathrm{V}_{\max }}
$$

where:

$\mathrm{S}_{\mathrm{a}}$ : accidental status

$\mathrm{N}_{\mathrm{e}}$ : corrected number of events

$\mathrm{V}_{\text {max }}$ : maximum value

Value: a) if there aren't any established crosswalks:

$\mathrm{N}_{\mathrm{e}}=$ number of hits by car $+0.3 *$ (number of pedestrians and cyclists hit)

b) if there are any established crosswalks:

$\mathrm{N}_{\mathrm{e}}=$ number of hits by car

\subsubsection{Traffic status}

In the railway companies' traffic records the number and the division by type and time period of the trains were travelled in a certain railway line within 24 hours are recorded. Knowing the examined road crossing's railway gauge number the daily traffic can be extrapolated to the crossing.

$$
\mathrm{S}_{\mathrm{t}}=50 * \frac{\mathrm{ADT} * \mathrm{t}_{\mathrm{i}} * \mathrm{~N}_{\mathrm{t}}}{\mathrm{V}_{\max }}+\frac{\mathrm{ADT}}{150 * \mathrm{ADT}_{\max }+50 * \mathrm{~B}}
$$

where:

$\mathrm{S}_{\mathrm{t}}$ : traffic status

ADT: Average Daily Traffic

It's value: in E/day unit of measurement, the maximum value means the maximum value of the numerator.

$\mathrm{t}_{\mathrm{i}}$ : average interference time

$\mathrm{N}_{\mathrm{t}}$ : number of trains

B: bus traffic

It's value:

a) 1, if there is any bus traffic

b) 0 , if there is no bus traffic 


\subsubsection{Traffic Management Characteristics and Other Hazard-enhancing Factors}

The 'railway speed limit' in context (3) is taking account of four speed rates. Among the 'other hazard-enhancing factors' the score calculation is based on:

- the type of the road where the railway crossing is situated (territorial nature)

- public lightning, the existence of separated sidewalk footpath

the existence of crossroads within 30 meters where the vehicles come from the railway crossing has no priority, and the security track is missing

$$
\mathrm{C}_{\mathrm{tm}}=\mathrm{SM}+\mathrm{SL}_{\text {rail }}+\mathrm{SL}_{\text {road }}+\mathrm{R}_{\mathrm{v}}+\mathrm{S}_{\text {road }}+\mathrm{Sb}+\mathrm{F}_{\mathrm{h}}
$$

where:

$\mathrm{C}_{\mathrm{tm}}$ : traffic management characteristic

SM: Security Method

$\mathrm{SL}_{\text {rail }}$ : Railway Speed Limit

$\mathrm{SL}_{\text {road: }}$ Roadway Speed Limit

$\mathrm{R}_{\mathrm{v}}$ : Recognizability, viability, geometry, angle of crossing

Sroad: Road Signs

Sb: Signboards

$F_{h}$ : Other hazard-enhancing factors

\subsection{Conceptual model}

If we examine the railway crossing as a given physical object, then we mean the concept of system as a model which can be described using physical variables. The contents of these physical variables also can be heterogeneous such as a combination of physical, chemical or economical characteristics. A part of the variables are given, these are the inputs or excitations. A common attribution of the other group of variables is the aim that we want to determine their behaviour. These are the outputs or outlets. We can speak about a third group of variables which is responsible for describing the connection or connections between inputs and outputs. In that case it is true that we describe an object by a system. In other words the system is the model of a given physical object.

Basically two main types of models can be distributed in conjunction with the type of processes we want to map. The geometrical, physical and mathematical models are belong to material models. The so-called mental models are functioning by the logical connections established by people, regarding to their methods and forms they are subjective, regarding to their contents they are objective. The so-called conceptual model [2] also can be classified as a mental model. This modelling method is applicable when a given problem's possible solution is requiring the creation of different scenarios. In our case each scenarios are equivalent to the hazard raking of the railway crossings. This procedure can be particularly suitable in the case of railway crossings, because some parts of the inputs are very hard - or impossible - to express in monetary terms. In the case of railway crossings the possible inputs are involving a quite wide range. 
Narrowing the input's range is necessary, and only those inputs can be taken into account which can basically influence the expected output. During the modelling process the railway crossing can be created as a replica which contains the essential features of the examined system.

\subsubsection{The Model Creation Process}

The first step of model creation is the determination of the inputs which are suitable for describing the railway crossing as a system and the necessary narrowing of the inputs' range is also must be performed - in such a way we described it in the previous chapter. The exact definition of the certain inputs are also belong to the first steps. The main groups of inputs can be the following:

- the environment of the railway crossing

- the security method of the railway crossing

- the accidental status of the railway crossing

- the traffic data of the railway crossing

- the way of traffic management and traffic arrangement in the railway crossing.

After that we can determine the most favourable $\left(Z_{\text {maxi }}\right)$ and the worst $\left(Z_{\text {mini }}\right)$ values of the specific inputs. Using the most favourable, the worst and the effective input values we can generate the input score (4) which can be given for certain inputs.

$$
\mathrm{l}_{\mathrm{x}}=\left\{1-\left[\frac{\mathrm{z}_{\mathrm{ix}}-\mathrm{z}_{\text {mini }}}{\mathrm{z}_{\text {maxi }}-\mathrm{z}_{\operatorname{mini}}} \times\left(1-\frac{\mathrm{z}_{\text {mini }}}{\mathrm{z}_{\operatorname{maxi}}}\right)\right]\right\} \times 100
$$

where:

$$
\mathrm{l}_{\mathrm{x}} \text { : input scoring number }
$$

$\mathrm{Z}_{\mathrm{ix}}$ : the effective value of the input (the $\mathrm{i}$-th input within the $\mathrm{x}$-th input group)

For setting up the hazard ranking the determination of the total score per crossing is necessary, according to the aggregation of the input indicators (5).

$$
\mathrm{Al}_{\mathrm{xe}}=\sum_{\mathrm{i}=1}^{\mathrm{n}} \mathrm{I}_{\mathrm{ix}} \times \mathrm{W}_{\mathrm{ei}}
$$

where:

$A I_{x e}$ : the aggregated value of the inputs

$\mathrm{I}_{\mathrm{ix}}$ : the score of the i-th input

$\mathrm{W}_{\mathrm{ei}}$ : the preference weight of the $\mathrm{i}$-th input from the perspective of the given expert group

In the conceptual model the preference weight of the inputs is determined by an expert group, the aggregated value can be understood as the total score of the road crossing. The higher value means a higher hazard rate. 


\section{The Establishment of the Hazard Raking with the Usage of Evaluation Matrix}

After the examination of the potentially attractive models we described in the previous chapter, a so-called Evaluation Matrix was created. Considering practical and theoretical aspects it can be stated that the Evaluation Matrix is a flexible method which provides in every case of railway crossings a useful solution and a basis for reconstruction catalogues for railway crossings.

\subsection{The Structure of the Evaluation Matrix}

The Evaluation Matrix is based on the simplest data sorting procedure; on the sorting by magnitude. The elements of the sample are corresponding to the railway crossings involved to the examination. The scores given for crossing features are summarised by crossings, and the received amount is being sorted by their size. The resulting sequence is the ranking and the scores mean the rank numbers.

The Evaluation Matrix separates three main input groups (Fig. 2):

- accidents

- traffic status

- traffic management characteristics

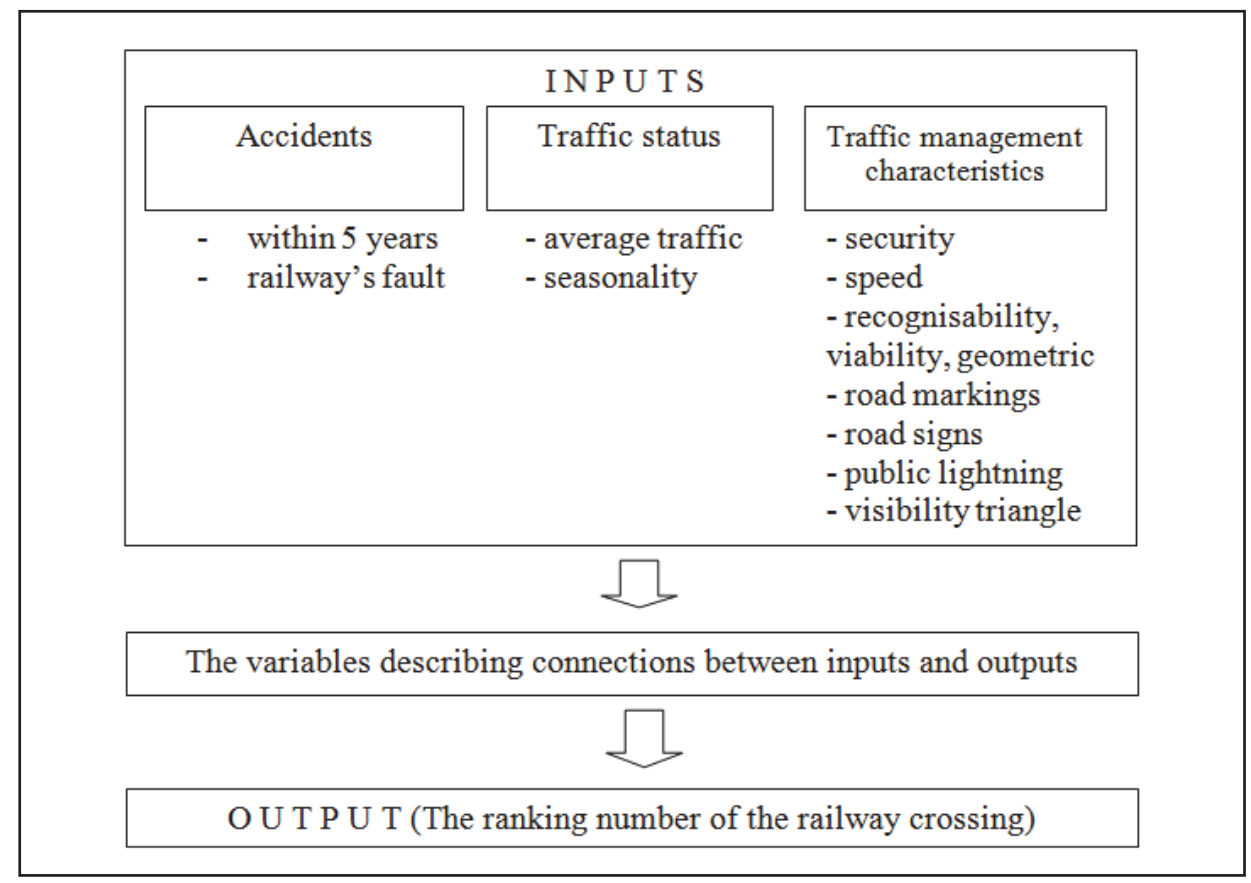

Figure 2. The Input System of the Evaluation Matrix 
The main contents of the input groups are essentially equal to the groups discussed in the case of the 'GySEV model', but also there are some significant differences. In the score values' calculation extra scores are given for the conditions which are the railways' fault. The past five years are the basis of the calculation when we calculate the accidental status' score values. The seasonal traffic growth in the crossing is taken into account in the traffic status input group. The Evaluation Matrix calculates with the daily average roadway and railway traffic. This element allows the easier practical application of the matrix. The Government Regulation No. 20 of 1984 about 'the traffic control of roads and the placement of road sings'- which is still in force - is mentioning the 'standard railway crossing's traffic'. The feature of traffic standard had been built into the model with the existence or the non-existence of the seasonal traffic growth. Contrary to the government regulation, the average daily railway traffic isn't counting with that trains only which are 'passing through the crossing by schedule'. In relation to speeds, the basis of the calculations is the highest allowed speed $(80 \mathrm{~km} / \mathrm{h})$ of regional railway lines; therefore only two speed groups had been determined. The highest road speed allowed in a railway crossing is divided into four classes. New elements were picked up into traffic management characteristics such as:

- the contrast effect of sunshine persists for several hours due to the crossing's location in the case of road traffic

- the 'Start of level (railway) crossing' board is faded or damaged (even in a single board's case)

\subsection{The Modelling Process}

When the Evaluation Matrix was established, the input range was demarcated and the certain inputs were defined on the first stage, and after that they were merged to input groups. The Evaluation Matrix's processing algorithms are taking into account the requirement of the simple, fast and reliable practical application. The existence or nonexistence of any input elements can be evaluated by given scores. Scores can be given to the railway crossing's traffic status by reference (6).

$$
\mathrm{ADT}=\mathrm{ADT}_{\text {road }} \times \mathrm{ADT}_{\text {rail }}
$$

where:

$\mathrm{ADT}_{\text {road: }}$ Daily Average Roadway Traffic

$\mathrm{ADT}_{\text {rail: }}$ Daily Average Railway Traffic

If the value of NÁF is below 800.00 then the score can be given for traffic status will be allocated proportionally, but if NÁF is more than 800.00 then the maximum score number must be given. The outputs and the score values which can be given to each input elements (input groups) can be generated by the help of the processing algorithms. After the model is designed, it will be filled with values, and the feasibility of the outputs will be checked (Figure 3). 


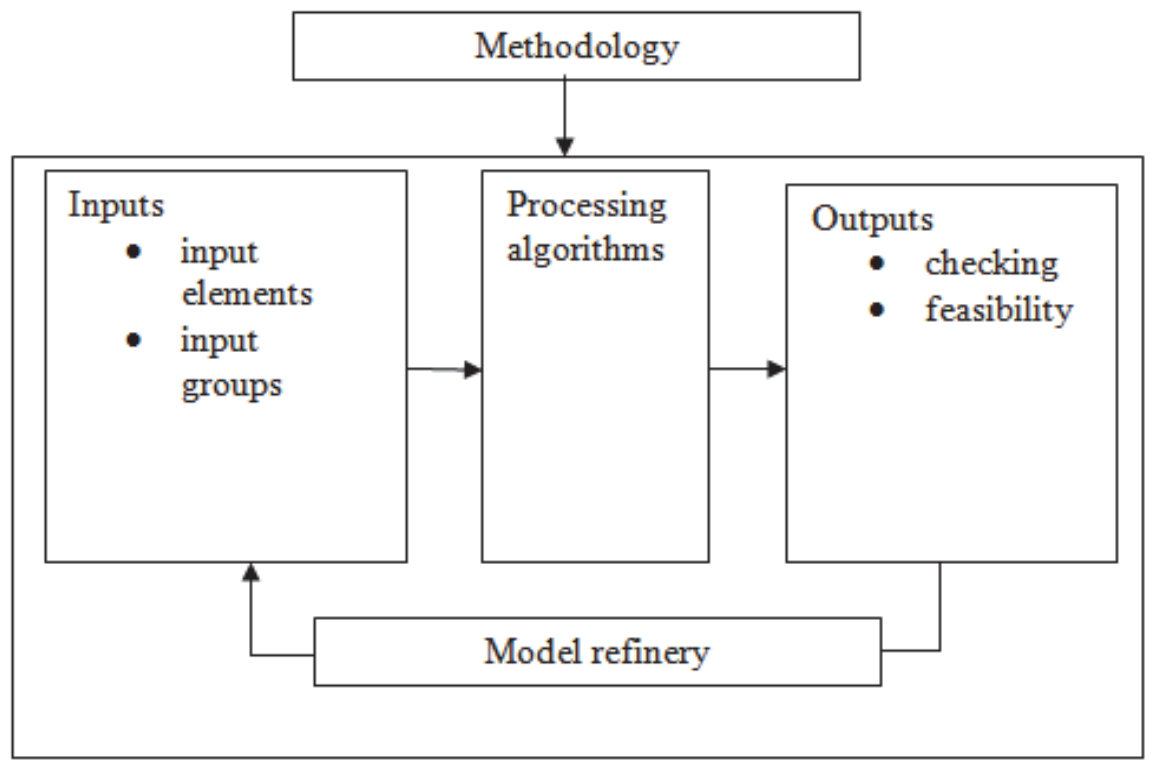

Figure 3: The Modelling Process

\section{Describing the Crossing Designated for Reconstruction}

The reason of designing the Evaluation Matrix we discussed in the previous chapter was the fact that in many cases the railway crossings' classification by conventional examination elements was unable to give a realistic hazard picture for the given crossing (for example according to some studies and analyzes the serious accidents are usually happening in crossings with smaller traffic [3]). There was a single score number or value limit determined for the inputs (evaluation criteria) of the Evaluation Matrix. The weighting of the given score value system is based on the concerning standards, existing regulations and legislations [4] [5] [6] [7] [8].

In the determination of some input factors' value system some results was also used which had been calculated in previous work packages (as connection points) such as AP3, traffic counts etc. Beside the above-mentioned, more important criteria elements, which were used in previous evaluations, other input factors are parts of the matrix, which are also must be followed (for example consumer questionnaires, observations and expectations raised by opinions -as input factors).

According to the aggregation of each input elements' score value, every crossings got a kind of so-called 'hazard total score'. Based on this score in terms of the examined crossings' safety the crossing which has the most score number is the 'most dangerous', and the crossing which has the lowest score is the 'most secure'. However it is very important to highlight that every of the selected $28(23+5)$ crossings in the project are suitable for the currently existing provisions and regulations by the special authorities' classification. 


\subsection{The 'Hazard Ranking' of the Examined Crossings and the Most Dangerous Crossing}

From the examined crossings (GySEV railway lines) - according to the hazard ranking was established by the results of the crossings' evaluation matrix - the most score value (1574 points) and 'the most dangerous crossing' title was given to the AS765 railway crossing on the Line No. 8. (the 'most secure' crossing is the AS759 on the Line No. 15, which had got 306 points.) The life-likeness of the theoretic criteria system developed by the working group was justified by the unfortunate fact that there were two accidents on that crossing in the past half years, and one of them had a fatal outcome. At the same time it is important to remember that in its current state the crossing is suitable for every regulatory requirements and regulations, just as we mentioned it above (the last special authority traversal was on 24th July, 2013) [9]

\subsection{The Security Features of the Crossing}

In relation to the safety features of the crossing - based on each output's scores - the following statements can be determined:

- 'Accidents' input: from the inputs - as one of the most significant examined aspects - the examined crossing (AS765) had got the maximum score (800 points; two or more accidents within 2 years) in terms of accidental scores.

- 'Traffic status' input: the traffic status in terms of input factors (daily average railway/roadway traffic, seasonal traffic growth etc.) can be considered average or slightly below it compared with the other examined crossings (total score: 184 points).

- 'Traffic Management Characteristics': In terms of traffic management characteristics the crossing is the fifth most dangerous from the examined crossings based on the amount of each input factors' score (total score: 590 points).

From the matrix's columns which are containing the total scores ('Ranking by total scores') it can be obviously determined that with its 1574 points (which is the amount of each inputs' scores) this crossing is the most dangerous not only from the selected 23 GySEV crossings, but from all of the examined ones (GySEV + Raaberbahn).

\subsection{Establishment of the Crossing No. AS765, Environmental Characteristics, Accidental Statistics}

The crossing selected for reconstruction is situated in the level junction of the No. 8526 public road's $1+534$ km gauge (the link road of Kópháza - Balf - Fertőrákos) and the No 8. GySEV railway line's 765 + 94 gauge (GPS coordinates: N47, 38' 25,1"; E16, 39' 40,9").

\subsubsection{Traffic Management and Environmental Characteristics}

The railway and roadway characteristics of the No. AS765 crossing according to the condition-measuring before the reconstruction proposal: 
- Railway:

- The crossing is equipped with four masts and a light barrier, and it is operating automatically by the train (omnidirectional)

- $\quad$ there is no pedestrian passage or built traffic safety island

- One track; the path's speed is max. $100 \mathrm{~km} / \mathrm{h}$

- The pavement of the railway crossing is STRAIL

- Roadway:

- $\quad$ number of lanes: $2 \times 1$

- 'Start of level (railway) crossing' signboard in the crossing ('St. Andrew's cross')

- $\quad$ 'Level (railway) crossing' predictor and additional boards from both directions (repeated on the left and right travel directions)

- the allowed speed of the public road is $90 \mathrm{~km} / \mathrm{h}$ (public domain), speed limit before the crossing $(40 \mathrm{~km} / \mathrm{h})$ positioned on the triband predictor board from both directions

- $\quad$ 'Dangerous bend' predictor board from both directions

- $\quad$ Road bike passage to the public road before the crossing (from Kópháza)

- $\quad$ connecting dirt roads (within 22 meters) from both directions

- $\quad$ the crossing angle is $90^{\circ}$

- the visibility triangle is reduced

\subsubsection{Accidental Statistics}

The accidental statistic of the crossing in terms of the past 12 years can be summarized in the following:

- 30/08/2002 - fatal accident, 2 people

- 19/09/2009 - slight injuries, 1 person

- 29/06/2013 - slight injuries, 1 person

- 16/07/2013 - fatal accident, 2 people

\section{Proposals for the Reconstruction}

From the actions aimed to improve the safety of railway level crossings the barriermounting program and the LED-program had got big boost in Hungary after 2003. According to experts' statements the LED reduces the possibility of accidents with 
$50 \%$, and the barrier + LED construction reduces it with $85 \%$. Beyond all of that it is advisable to examine the possibility of deploying further safety-enhancing actions.

\subsection{Safety-enhancing Actions from the Recent Past}

Because of the accidents from the past few years in the crossing designated for reconstruction (which were too frequent compared to the traffic conditions - two accidents, one of them is fatal within a month in the summer of 2013), there were more authority traversals in the near past. [9] [10]. Each time on these site inspections it was determined that the crossing is suitable for all of the concerning regulations and legislations.

As a result of these traversals different safety-enhancing actions had been implemented (replacement of the worn predictors, wood felling, thinning of vegetation on account of better visibility, placement of predictor boards to the connecting municipal roads, reducing the distance between 'striped' predictor boards and placing them to the same axis line and the same distance from the roadway, the replacement of the railway light signalling device to LED optics etc.).

Despite all of these actions the accidental statistics confirms that the crossing is remained extremely dangerous. The rating of the Evaluation Matrix also refers to this fact.

Considering these facts we can determine that further changes and modifications are required in the crossing in order to increase the safety and to reduce the emergency phase - also from the railway and the roadway part.

\subsection{Further Security-Enhancing Suggestions for Modifications and Improvements}

The preparation of a reconstruction concept is also a part of the SiEBaBWe project's working package, which is intended to taking action recommendations in order to increase the safety of the object classified as the most hazardous from the $23(+5)$ examined crossings. For this purpose the partners involved to the established professional working group measured the potentially attractive opportunities on a common traversal, and they worked out proposals together. The accepted draft proposal has affect on the railway infrastructure and also on the roadway infrastructure.

\subsubsection{Proposals for Railways}

Based on the current railway infrastructure the following modifications and additions had been recommended:

- the installation of a half-barrier in the crossing and the necessary replacement of its signalling masts within the prescribed distance [11] as its consequence (comment: this installation is a part of the medium-term development program of GySEV) /Figure 1, points marked with (a)/

- the moving of the additional light signalling mast to the prescribed [11] maximum allowable 8 meters distance from the path axes (Kópháza side, mast marked with 'D'), and its rotation to the appropriate direction (viewing angle) in order to the better visibility and the earliest perceptibility for the road traffic (a 
hazardous road bend with small radius curving to the left, with the crossing immediately on the end of the curve) /Figure 1, point marked with (b)/

- the moving (increasing) to the appropriate distance of the barrier-actuator equipment's so-called interlocking system's exposure points to ensure the prescribed pre-flashing and pre-closing time. This action's necessity is justified by the requirement of ensuring the prescribed value which had been changed due to the supplement of the half-barrier [11]. The current distance of the exposure points (light assisted security only) and the required values calculated with the supplement of the half-barrier are shown on Table 3.

Table 3. Determining the Installation Distance of the Exposure Points [11]

\begin{tabular}{|c|c|c|c|c|c|c|c|c|}
\hline \multirow[b]{2}{*}{ AS 765} & \multicolumn{2}{|c|}{ Currently } & \multicolumn{2}{|c|}{ Calculated } & \multicolumn{2}{|c|}{ Core data } & \multirow[b]{2}{*}{$\mathbf{B}_{\mathrm{t}}$} & \multirow[b]{2}{*}{2} \\
\hline & Middle & $765+48$ & $\begin{array}{c}\mathrm{A} 2 \\
\text { transmitter }\end{array}$ & A2 receiver & $\begin{array}{l}\text { Angle } \\
\left({ }^{\circ}\right)\end{array}$ & J90 & & \\
\hline \multirow[t]{3}{*}{$-2080,0$} & A2 & $777+11$ & $756+31,0$ & $756+13,0$ & $\begin{array}{l}\text { Number } \\
\text { of } \\
\text { Masts }\end{array}$ & 4 & $\mathbf{L}_{\mathrm{v}}$ & 6,01 \\
\hline & A4 & & & & Barrier & Yes & $\begin{array}{l}\mathbf{t}_{\min } \\
(\mathrm{c} .)\end{array}$ & 29,4 \\
\hline & A3 & & $\begin{array}{c}\text { A1 } \\
\text { transmitter }\end{array}$ & A1 receiver & $\begin{array}{l}\text { Road } \\
\text { Width } \\
\text { (m) }\end{array}$ & 6 & $\mathbf{t}_{\min }$ & 33 \\
\hline$-1993,0$ & A1 & $754+72$ & $774+65,0$ & $774+83,0$ & $\begin{array}{l}\text { Track } \\
\text { Speed } \\
(\mathrm{km} / \mathrm{h})\end{array}$ & 100 & $\mathbf{l}_{\text {beh. }}$ & 917 \\
\hline
\end{tabular}

$\mathbf{b}_{\mathrm{t}}$ : Safety distance $(\mathrm{m})$

$\mathbf{l}_{\mathrm{v}}$ : the length of the endangered road section $(\mathrm{m})$

$\mathbf{t}_{\min }$ (c.): minimal pre-closing time / calculated/ (sec)

$\mathbf{t}_{\mathrm{min}}$ : minimal pre-closing time $(\mathrm{sec})$

$\mathbf{l}_{\text {beh.: }}$ exposure distance $(\mathrm{m})$

\subsubsection{Proposals for Roadways}

The following recommendations had been placed into the roadway's modifications package as the part of the reconstruction concept:

- The curve widening of the public road No. 8526 in the road bend before the crossing on the Kópháza side. This widening is necessary because long vehicles (for example hinged buses) are also travelling on this section of the public road, and a possible bidirectional encounter on the given place in the same time could cause a dangerous situation (particularly regarding to the relative short distance of the unloading section before the bend). It is also confirmed by the fragmented and dimpled roadside we experienced during the site visit. /Figure 4, point marked with (1)/ 
- Putting the roadway's Ferro-concrete crash barriers and the concerned mast to the same line in the crossing while the prescribed distance is maintained [6]. These crash barriers can be exchanged with guardrails where necessary. In case of exchange the incorporation of reflective prism elements onto the barrier would be advisable for better visibility. /Figure 4, point marked with (3)/

- Establishing ribbed transversal shaker lanes (single, double and triband) on the pavement (in vivid yellow colour) in the travel direction's band from both directions ('hazardous area predicting' lines). For the better visibility it is advisable to place reflective prisms on the shaker lanes' edge as well as the fixing of modern and cost effective solar powered flashing prisms. The application of these elements are highly increase the visibility and it has a powerful awareness raising role - mainly in darkness or among bad or restricted visibility conditions (Nowadays these latter accessories are more and more often used in those areas which are particularly dangerous in terms of public road traffic). /Figure 4, points marked with (2)/

- Moving the striped predictor boards which are indicating the railway crossings (single, double or triband boards) to the possible prescribed [4] minimum distance still fits to the given circumstances. This modification is necessary because according to previous experiences the settlement structure and the traffic conditions and habits have similar features than populated areas have, in spite of the rural classification of this public road section. /Figure 4, points marked with (6)/

- Moving (from both directions) the Speed Limit board (40 km) to the single band predictor board (because of the reasons mentioned in the previous section) /Figure 4, points marked with (6)/

- Placing a 'board indicates the bend's curve' (red herringbone-like herding boards with yellow framework) directly to the start of the road bend /Figure 4, points marked with (7)/

- Placing 'no overtaking', 'no turning' and 'mandatory driving direction' boards on the public road and on the connecting dirt roads because of the barrage line /Figure 4 points marked with (4)(5)(9)/

- Moving the bicycle path's current exit lane (aimed to the public road) from Kópháza preferably to a destination which is farther from the crossing in order to reduce the concentrated emergency situation. More variants are emerging in relation to the exit lane (adjusted to the traffic and usage habits): on one hand the placement of the exit lane to the existing opposite-directional connection point from Balf (passed through the public road), and on the other hand the restructuring of the current vectoring point in the bend and its 'shifting' towards the connecting dirt road. /Figure 4, points marked with (8)/

- The placement of an informative, awareness raising board or poster, which has appropriate hazard warning and awareness raising affect with its concentrated message-bearing graphical and image-based elements on every traveller who uses the railway crossing. /Figure 4 points marked with (11)/ 
- The equalization of the road surfaces' level difference, its minimization between the road surface and the crossing's surface (STRAIL) with the proper modification of the connecting public road's surface ('trimming') /Figure 4, point marked with (12)/

- The replacement of the 'level crossing with half barrier and light barrier ahead' board on the triband predictor board /Figure 4, points marked with (10)/.

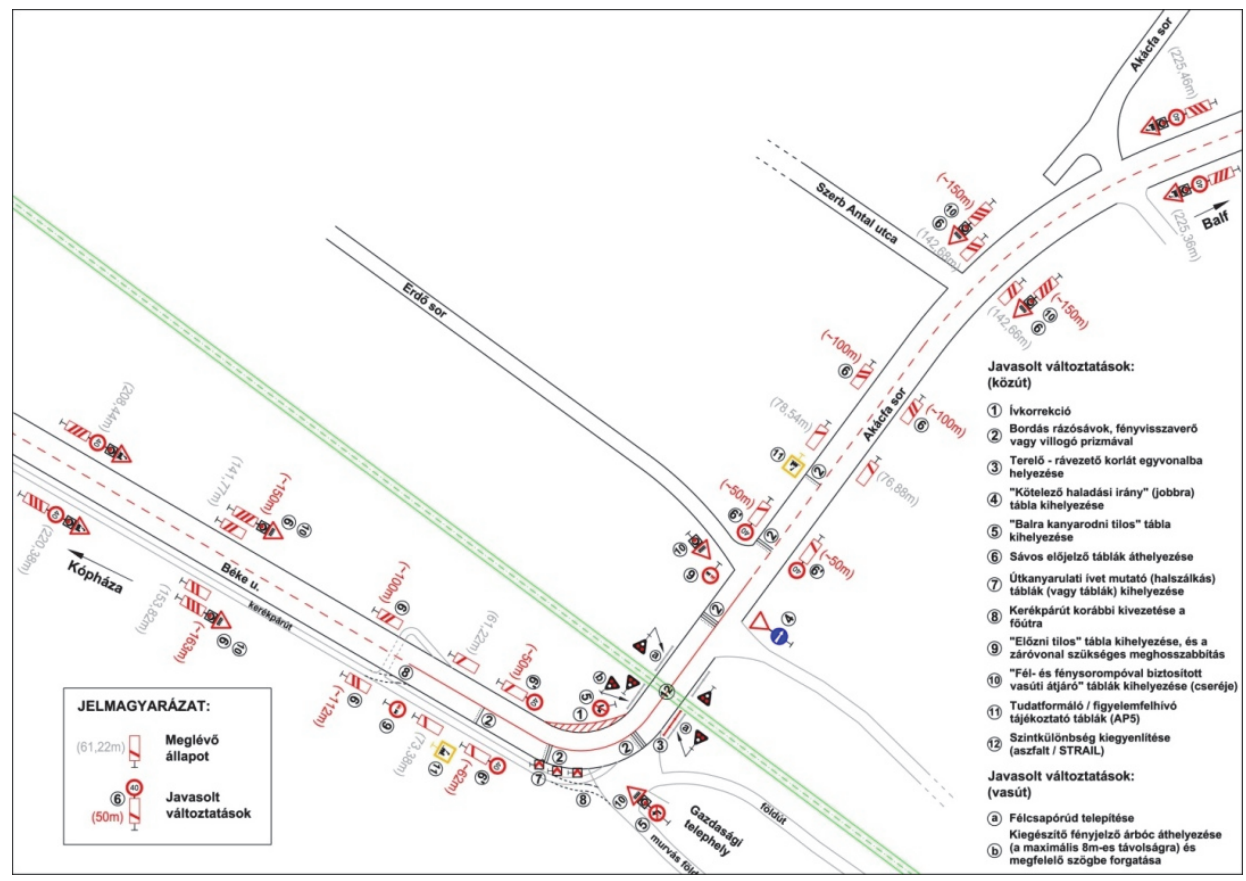

Figure 4:

The Site Plan of the Crossing No. AS765 and the Railway-Roadway Connection

For the implementation of the listed proposals the preparation of a preliminary plan is required both from the railway and the roadway side.

\subsection{Preliminary Cost Estimation and Time Schedule Plan}

From the alternatives of the reconstruction concept the preliminary cost estimation which contains the planning and the implementation costs in relation to the finally accepted modification proposals - will be performed by the project partner (GySEV) within their respective powers.

The expected realization time of the accepted reconstruction concept's complex implementation will be the end of the year 2015 , depending on the availability of the sources. 


\section{Conclusion}

Considering the expected effects in relation to the reconstruction at first we have to take into account the fact that based on statistical studies the crossing's supplement with a half-barrier is significantly increases the safety in the given crossing [3] [13]. In addition we can speak about a financially beneficial investment, which can be justified by economical calculations [13]. However the other modifications and additions proposed in the project are providing more information to the user of the crossing: in one hand the traveller will become more aware of the hazardous zone's approaching, on the other hand these information are helping in conscious formation of the necessary and desired traffic behaviour, therefore the chance of occurring accidents will be further reduced. This latter conclusion indicated the renewal of the program series called ILCAD (International Level Crossing Awareness Day), which is organised annually from 2009 with the coordination of the International Union of Railways (UIC) and with the support of the European Commission (EC) and the United Nations Economic Commission for Europe (UNECE). The slogan of the ILCAD is: 'Act safely at level crossings'. The main goal of this international conference series is the same as the project SiEBaBWE's main objective; to effectively increase the safety of the level roadway-railway crossings, to reduce the number of accidents and in long term to reach the totally accident-free traffic.

\section{References}

[1] Tigyi Sz, Gábor M: The Safety Status of the Railways in Hungary and the Development of Their Hazard Ranking. XI. RODOSZ Conference, Kolozsvár 1214 November 2010.

[2] Pokorádi L: Modelling Systems and Processes. Campus Publisher, Debrecen, 2008.

[3] Konrád Gy: Accidents and Railway Crossings Operated on the lines of GYSEV Zrt. GYSEV Zrt., Study on 15/05/2013

[4] Government Regulation 20/1984 (X11.21)

[5] Standard of KPMSZ. Kk No. 108-73 and It's Modification (E 07MSZ.-07 Kk.108$73 \mathrm{M} / 1983$ )

[6] Road Standards No. ÚT2-1.201

[7] Road Standards No. ÚT2-1.225

[8] Technical Guidance of MÁV No. D54. (Technical Data and Regulations of Construction and Track Maintenance I-II.)

[9] Memorandum of Police Headquarters, Győr-Moson-Sopron Country, Law Enforcement Department, Case No.: 0800/4088-7/2013.), Győr, 30/07/2013.

[10] Report, No. NKH KÜI KU/VF/1853/0/2009 Report and the Associated Report, Sopron, 16/11/2009.

[11] 'Light Barrier Requirements' E07 MSZ.-07 Kk.108-73 M/1983 Standard and It's Additional Modification

[12] Traffic Safety 02/2011, NKH, 2011.

[13] Tremmer T: A sorompó megvéd a haláltól. Napló Online, veol.hu [Last visited: 19/05/2014] 